\title{
Innovative wine products quality management system on Sevastopol region example
}

\author{
Natalya Alesina, Elena Posnaya*, and Andrey Kuzmin \\ Sevastopol State University, 299053 Sevastopol, Russian Federation
}

\begin{abstract}
The article presents results of the current state studies of the wine industry in the Sevastopol region. It has been established that the problem of the viticulture development and winemaking in this region is not so much in the wine production technological aspects, but in the quality of raw materials for the production of wine products and the yield of grape plantations, as well as in ensuring that the price and wine products quality are consistent with the population purchasing power. Based on the results of the study, the feasibility of using innovative quality control technologies in the Sevastopol agro-industrial cluster was substantiated, ways of integrating the "precision viticulture" project into the organizational and economic structure of the Sevastopol agro-industrial cluster were developed. The structure of investment costs for the project of the meteorological platform "Demetra" implementation has been determined and the organizational structure of the "Digital Quality Center" has been developed. The possibility of using various financing options for a joint project of cluster participants to create a quality management system for the wine industry in the Sevastopol was considered.
\end{abstract}

\section{Introduction}

The issues of the domestic wine products quality with an emphasis on the cultivation of raw materials have gained high relevance today, especially for winemakers of the Crimean peninsula and the city of Sevastopol. This conclusion is confirmed by a comparison of the economic efficiency of the industry in terms of yield on the Crimean peninsula (including the Sevastopol region, where the grape yield reaches $4 \mathrm{tn} / \mathrm{ha}$ ) with the corresponding indicators of European countries, whose vineyards are in similar soil and climatic conditions, when growing similar grape varieties the average yield in European countries is $13 \mathrm{tn} / \mathrm{ha}$.

The relevance of the topic under consideration is further aggravated by the fact that $78 \%$ of all vineyards in Crimea (including Sevastopol) are not irrigated, and $47 \%$ of them have vines over 25 years old with sparseness ranging from 11 to $25 \%$ (depending on age).

Leave In Russia, the latest results of ongoing research on the wine products quality are reflected in the works of O.N. Sheludko, T.I. Guguchkina, N.K. Strizhov, considering the issues of determining the type (category) of wine products and confirming its authenticity based on sample analysis and subsequent mathematical information processing $[1,2]$.

\footnotetext{
*Corresponding author: sntulena@ mail.ru
} 
Abroad, the topic of agriculture digitalization in general and, in particular, its wine industry is considered in the research of such authors as S. Shanmuganthan, A. Ghobakhlou, P. Sallis.

\section{Materials and methods}

In the process of conducting research on this topic, the following methods of scientific knowledge were used: methods of source analysis (when analyzing information about research in the field of viticulture and winemaking conducted by domestic and foreign experts), the method of analysis and synthesis, as well as methods of statistical data analysis.

The assessment of the current state and determination of the main trends in the functioning of the viticulture enterprises and wine-making were carried out on the basis of the current statistical reporting data for the last three years, materials of the Federal Service for the Regulation of the Alcohol Market, the Office of the State Statistics Federal Service for the Republic of Crimea and Sevastopol, as well as operational data of the Sevastopol Economic Development Department.

\section{Results}

Consider the prerequisites for the creation and development of the agro-industrial cluster innovative component in the Sevastopol.

In recent years, there has been a systematic laying of vine plantations: in 2017 are 228.05 hectares, in 2018 are 161 hectares, in 2019 are 534.45 hectares. As of December 10, 2020, 499.73 hectares were planted, while in 2020 it was planned to plant 561.48 hectares of new vineyards, which is almost 2.5 times more than in 2017 (according to the operational data of the Sevastopol Economic Development Department). This trend speaks of the investment attractiveness of this agro-industrial complex sector and the positive prospects for its development. But it should be borne in mind that young vineyards require increased attention and control from the moment of planting to the moment of first fruiting (i.e., within 4-5 years), because otherwise there is a threat of a decrease in yield, the quality of the grown raw materials, as a result, there is a decrease return on investment or even complete loss.

Let's characterize the wine market in Sevastopol. Since both finished wine and wine materials for its production in other regions are produced at the enterprises and farms of Sevastopol, we will analyze the volume indicators in the structure of the Russian Federation wine industry (Table 1).

As follows from the data in the Table 1, during the analyzed period, the share of Sevastopol in the total volume of wine production in the Russian Federation amounted to a maximum of $3.3 \%$, and for the production of wine materials it was $2.4 \%$ (2019), i.e. was insignificant even in comparison with the Crimea. This is explained by a number of problems that are typical for large Sevastopol wineries with a closed cycle (from grape cultivation to wine production), and even more so for enterprises that specialize exclusively in wine bottling. The efficiency of their activities significantly depends on the possibility of acquiring and the cost of modern high-performance technological equipment (most often imported), planting material, raw materials, basic and auxiliary materials, including containers and cork. It should be noted that liqueur wines, unlike Crimea, are not produced in Sevastopol, but their share in Crimea is also small and amounts to approximately $1 \%$ of the total volume, and in the Russian market as a whole, $0.3 \%$. 
Table 1. Comparative analysis of wine materials and wine production by enterprises of the Crimea and Sevastopol in the structure of the Russian Federation wine industry.

\begin{tabular}{|c|c|c|c|c|c|c|c|}
\hline \multirow[b]{2}{*}{ Region } & \multirow[b]{2}{*}{$\begin{array}{c}\text { Measu- } \\
\text { rement } \\
\text { units }\end{array}$} & \multicolumn{2}{|c|}{2017} & \multicolumn{2}{|c|}{2018} & \multicolumn{2}{|c|}{2019} \\
\hline & & $\begin{array}{c}\text { Grape } \\
\text { wine } \\
\text { materials }\end{array}$ & Wine & $\begin{array}{c}\text { Grape } \\
\text { wine } \\
\text { materials }\end{array}$ & Wine & $\begin{array}{c}\text { Grape } \\
\text { wine } \\
\text { materials }\end{array}$ & Wine \\
\hline \multirow{2}{*}{$\begin{array}{l}\text { Russian } \\
\text { Federation }\end{array}$} & $\begin{array}{c}\text { thous. } \\
\text { dal. }\end{array}$ & 76357 & 44806.3 & 50671 & 42934.3 & 53406 & 46198.4 \\
\hline & $\%$ & 100 & 100 & 100 & 100 & 100 & 100 \\
\hline \multirow{2}{*}{$\begin{array}{c}\text { Republic of } \\
\text { Crimea }\end{array}$} & $\begin{array}{l}\text { thous. } \\
\text { dal. }\end{array}$ & 5977 & 5223.8 & 9458 & 5543.8 & 5701 & 6096.7 \\
\hline & $\%$ & 7.8 & 11.7 & 18.7 & 12.9 & 10.7 & 13.2 \\
\hline \multirow{2}{*}{ Sevastopol } & $\begin{array}{c}\text { thous. } \\
\text { dal. }\end{array}$ & 1219 & 1235.2 & 922 & 1055.9 & 1280 & 1525.2 \\
\hline & $\%$ & 1.6 & 2.8 & 1.8 & 2.5 & 2.4 & 3.3 \\
\hline
\end{tabular}

Table 2 presents the characteristics of the grape wine consumption structure in the market of Sevastopol.

The population of Sevastopol prefers grape wines, their share in total sales averaged $65.3 \%$, while the share of sparkling wines averaged $34.4 \%$, the share of liqueur wines was less than $1 \%$.

Table 2. Dynamics and structure of grape wine retail sales in Sevastopol.

\begin{tabular}{|c|c|c|c|c|c|}
\hline Years & $\begin{array}{c}\text { Measu- } \\
\text { rement } \\
\text { units }\end{array}$ & Wine & $\begin{array}{c}\text { Sparkling } \\
\text { wine }\end{array}$ & $\begin{array}{c}\text { Liqueur } \\
\text { wines }\end{array}$ & TOTAL \\
\hline \multirow{2}{*}{2017} & $\begin{array}{c}\text { thous. } \\
\text { dal. }\end{array}$ & 246.8 & 129.3 & 0.6 & 376.7 \\
\cline { 2 - 6 } & $\%$ & 65.5 & 34.3 & 0.2 & 100 \\
\hline \multirow{2}{*}{2018} & $\begin{array}{c}\text { thous. } \\
\text { dal. }\end{array}$ & 259.0 & 141.0 & 1.6 & 401.6 \\
\cline { 2 - 6 } & $\%$ & 64.5 & 35.1 & 0.4 & 100 \\
\hline \multirow{2}{*}{2019} & $\begin{array}{c}\text { thous. } \\
\text { dal. }\end{array}$ & 272.9 & 140.6 & 1.4 & 414.9 \\
\cline { 2 - 6 } & $\%$ & 65.8 & 33.9 & 0.3 & 100 \\
\hline
\end{tabular}

Table 3 compares the production of wine materials, finished wine and the volume of its retail sale in the Sevastopol market, which creates the possibility of forming ideas about the sufficiency of wine materials for own production and the potential level of demand for wine from Sevastopol producers in the city's retail chains.

The data in the Table 3 indicate that Sevastopol producers experience an obvious shortage of wine materials, which is covered by imports. Of the total wine produced volume in the retail network of the city, $30-40 \%$ can be sold (depending on the volume of production in a particular year), therefore, the rest of the products are supplied to the markets of other Russian Federation regions and are exported in small quantities.

This is confirmed by data on export-import operations for the commodity group "grape wines, natural" in Sevastopol (Table 4). 
Table 3. Comparative analysis of the wine materials and wine production volumes and retail sale of wine in Sevastopol, thousand dal.

\begin{tabular}{|c|c|c|c|c|}
\hline \multirow{2}{*}{ Years } & \multirow{2}{*}{$\begin{array}{c}\text { Production of } \\
\text { grape wine } \\
\end{array}$} & \multirow{2}{*}{$\begin{array}{c}\text { Wine } \\
\text { materials }\end{array}$} & \multicolumn{2}{|c|}{ Retail sale of wine } \\
\cline { 4 - 5 } & production & thous. dal. & \% of wine production \\
\hline 2017 & 1219 & 1235.2 & 376.1 & 30.4 \\
\hline 2018 & 922 & 1055.9 & 400.0 & 37.9 \\
\hline
\end{tabular}

The main countries to which this group of goods was exported from Sevastopol in 2017 2019 were: Ukraine ( $86 \%$ of the total export volume for the specified period for a total of USD 1.5 million) and China (9.2\% for a total amount of USD 163 thousand). In this case, the exported finished wine products.

Table 4. Dynamics of export-import operations for the commodity group "grape wines, natural" in Sevastopol, tons.

\begin{tabular}{|c|c|c|}
\hline Years & Export & Import \\
\hline 2017 & 45.8 & 2600 \\
\hline 2018 & 306.0 & 336 \\
\hline 2019 & 870.0 & 692 \\
\hline TOTAL & 1221.8 & 3628 \\
\hline
\end{tabular}

In the structure of imports, the main commodity item in this group of goods was occupied by wine materials supplied from Spain ( $95 \%$ of the import volume for this group). For the period 2017-2019, a total of 2.1 million USD of wine was imported from Spain. Basically, they imported "other wines, grape must, in vessels with a capacity of more than 2 liters" (almost 100\%).

Table 5 shows the averaged structure of the retail price for wine produced at the wineries of Sevastopol with a full cycle, based on the results of an expert assessment of the authors, subject to the sale of finished products through retail chains. In this case, we are talking about manufacturing plants, since the products of author's winemaking are sold mainly through the catering sector: bars, restaurants or through points of sale directly on the territory of wineries within the framework of tourist routes through the city and its environs. As for the public catering sector, the markup for author's wine is about the same as in retail chains, or even more.

As can be seen from the data presented, in addition to indirect taxes, the main share in the price structure is made up of markups from wholesalers-intermediaries and retail chains (approx. 40\%). The cost of packaging and basic materials in total is $14 \%$. The cost of raw materials is in third place $(11.5 \%)$.

The autonomous non-profit organization "Russian Quality System" (Roskachestvo) in 2020 conducted a study of trends in consumer behavior in the wine category. This study was conducted by an online survey of respondents over 18 who purchase wine at least once a month. The sample included residents of cities with a population of over 100 thousand people from all federal districts of the country. The audience of the study was 1200 people. As a result, it was found that the Russian wine market is characterized by the following tendency: 
the more prices rise, the more demand differentiates, i.e. either inexpensive wines or superpremium wines are bought. One of the most important criteria for choosing a wine is its type: dry, semi-sweet or sweet. This was noted by more than half of the consumer audience. The wine brand was named an important criterion for selection by $21 \%$ of the respondents. Price was an equally important selection criterion (14\% of respondents).

Table 5. The average structure of the retail price for a bottle $(0.751)$ of natural grape wine produced at wineries of Sevastopol full cycle, when sold through retail chains.

\begin{tabular}{|l|c|c|}
\hline \multicolumn{1}{|c|}{ Price elements } & Rub. & $\begin{array}{c}\text { In \% to the retail } \\
\text { price of bottle }\end{array}$ \\
\hline Raw materials (grapes) & 70 & 11.5 \\
\hline Processing of raw materials & 40 & 6.6 \\
\hline Bottle cost & 35 & 5.8 \\
\hline Label cost & 10 & 1.6 \\
\hline Cork cost & 40 & 6.6 \\
\hline TOTAL cost of wine bottle production & 195 & 32.1 \\
\hline Manufacturer's profit & 40 & 6.6 \\
\hline Distributor's markup & 175 & 28.8 \\
\hline Retail markup & 73 & 12.0 \\
\hline TOTAL price of a bottle of wine excluding indirect taxes & 483 & 79.6 \\
\hline Excise (31 Rubles per 1 liter) & 23 & 3.8 \\
\hline VAT (20\%) & 101 & 16.6 \\
\hline $\begin{array}{l}\text { The retail price of a bottle of wine 0.75 I in the trade } \\
\text { network }\end{array}$ & 607 & 100.0 \\
\hline
\end{tabular}

Table 6 shows the structure of the distribution of wine products by price segments in the retail chains of the Russian Federation.

Table 6. Distribution of wine products by price segments in retail chains of the Russian Federation.

\begin{tabular}{|l|l|}
\hline \multicolumn{1}{|c|}{ Price segment } & Price per bottle (Rub) \\
\hline Inexpensive wines (mass production and demand) & up to 500 \\
\hline Medium & from 500 to 1000 \\
\hline Premium & from 1000 to 2000 \\
\hline Super premium & over 2000 \\
\hline
\end{tabular}

Summing up, it should be said that the key risk for participants in the agro-industrial cluster, wine-making enterprises and farms, is associated with a low effective demand for the highest quality wine products in the domestic market and the presence of a stable demand for 
a mass product. This is especially true of private wineries specializing in the production of premium wines, with a large share of manual labor with small volumes of grape cultivation and wine production, which leads to a significant increase in the cost of the final product.

Taking into account the formation of prices for wine products produced by Sevastopol enterprises and consumer preferences that determine the criteria for choosing domestic wine, the introduction of digital technologies for precision viticulture will, firstly, reduce costs in the process of growing grapes and increase yields, which will provide an opportunity to reduce the selling price of wine and secondly, to improve the quality of grape raw materials and finished products.

Based on the analysis, we propose to apply quality control technology in the precision viticulture system in the agro-industrial cluster of Sevastopol. Let's show what it is.

The production system, marketed as "precision viticulture", involves the application of various management methods in the field in accordance with the conditions of the vineyards.

Specifically for the conditions of the Sevastopol region, it is proposed to create and implement a meteorological platform "Demetra", which makes it possible to organize monitoring of meteo- and phenological parameters of the viticulture and wine-making terroir. In addition, "Demetra" has flexibility in the use of measuring sensors and has a customizable "agronomist $\leftrightarrow$ weather station" feedback system by manually entering observational data of an agronomist or consultant into a weather station, which complements historical weather data and allows for more accurate and specific forecast in the future.

Fig. 1 shows the "Demetra" meteorological platform mechanism.

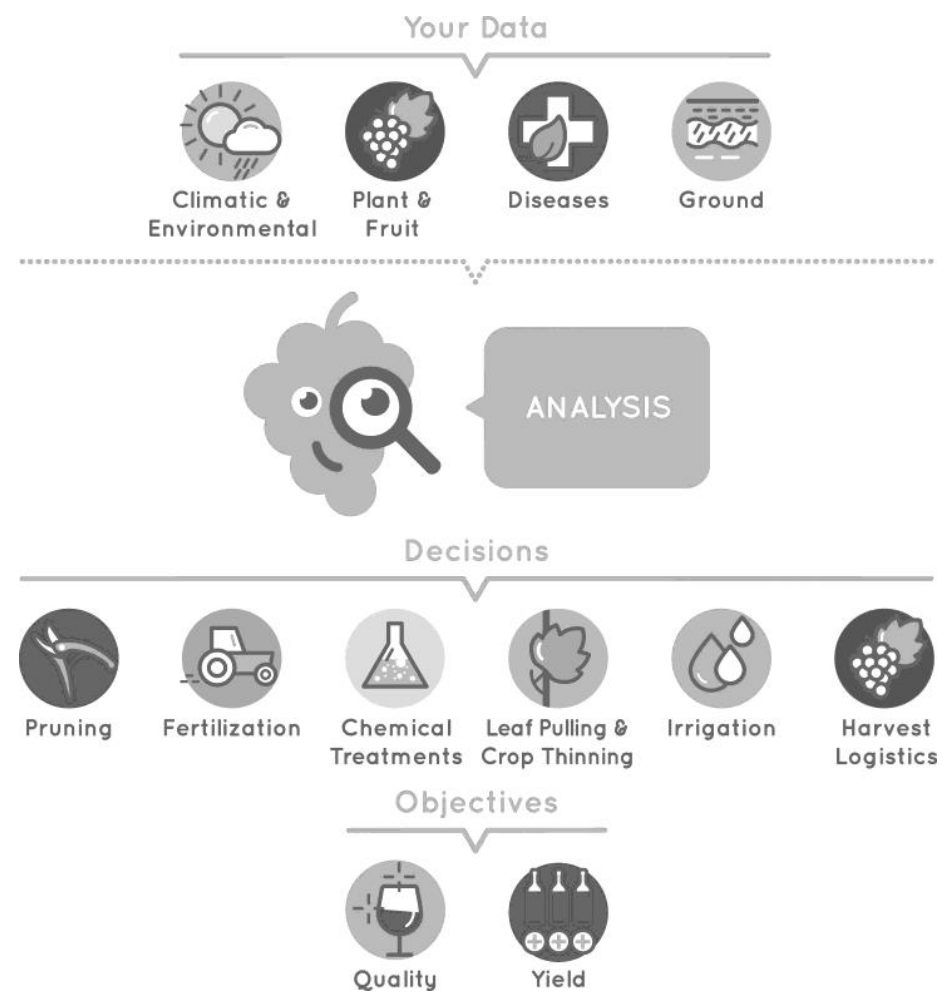

Fig. 1. The meteorological platform operation mechanism.

The proposed meteorological platform has the following advantages:

- it provides for the creation of a weather station using artificial intelligence. Monitoring functions are supplemented by human observations: technological processes in the vineyard, 
phenological phases, the condition of the bushes, the yield and quality of grapes are accurately linked to the data received from the sensors at a given point in time for timely and informed agrotechnical decisions in the future;

- the base station SMART-BOX allows you to connect several areas within a radius of $15 \mathrm{~km}$ to a single weather database in the cloud, which makes the forecast more accurate.

Investment costs for the project of the meteorological platform "Demetra" implementation in the wineries of Sevastopol are within 4 million Rub for one set of equipment (including a basic set of sensors) and software for it (Table 7).

Implementation of a precision viticulture project using the Demetra meteorological platform will allow:

- to improve the quality of wine products produced in the Sevastopol agro-industrial cluster; - to reduce the use of pesticides for processing plants;

- to optimize the number of staff as a result of reducing manual labor associated with the maintenance of vineyards;

- to stimulate the development of small and medium-sized wineries producing premium-class products, integrating them into the tourism sector of the city in order to popularize the quality of wine from local producers and expand the sales market.

The application of the "precision viticulture" system in the Sevastopol region is a pilot project and provides for its further scaling up to other regions of the Russian Federation.

Let us consider the integration of the "precision viticulture" project into the organizational and economic structure of the Sevastopol agro-industrial cluster.

Table 7. Structure of investment costs for the project of the meteorological platform "Demetra" implementation.

\begin{tabular}{|c|c|c|}
\hline No & Position & Cost, Rub \\
\hline 1 & $\begin{array}{l}\text { Base station SMART-BOX consisting of: } \\
\text { - transmission and reception equipment, communication channel controller, } \\
\text { microcomputer; } \\
\text { - power cabinet in IP65 version with UPS system }\end{array}$ & 300000 \\
\hline 2 & $\begin{array}{l}\text { Delivery, placement in the vineyard and alignment of sensors with data } \\
\text { transmission modules in each sensor. List of sensors: } \\
\text { - air temperature and humidity; } \\
\text { - atmospheric pressure and precipitation level; } \\
\text { - wind strength and direction; } \\
\text { - soil temperature and moisture; } \\
\text { - lighting and sap flow }\end{array}$ & 700000 \\
\hline 3 & $\begin{array}{l}\text { Server equipment for data accumulation and storage, consisting of: } \\
\text { - server computer, monitor, data drives in a RAID array, } \\
\text { - network equipment and NAS }\end{array}$ & 650000 \\
\hline 4 & $\begin{array}{l}\text { Client-server software consisting of: } \\
\text { - thin client - user's personal account; } \\
\text { - DBMS and control center with a big data analysis system }\end{array}$ & 500000 \\
\hline 5 & $\begin{array}{l}\text { Cameras for fixing the state of plants in the composition: } \\
\text { - NDVI (by sheet); } \\
\text { - spectrometer (by bunch) }\end{array}$ & 1850000 \\
\hline \multicolumn{2}{|c|}{ TOTAL } & 4000000 \\
\hline
\end{tabular}

Within the framework of these projects, it is envisaged to carry out activities in the following promising areas, directly or indirectly focused on solving the problems of ensuring the quality of wine products from the moment of planting grapes to ripening and making wine: 
- creation of a research and production center for applied and digital technologies in agriculture;

- creation of a data center for monitoring and accumulating qualitative and quantitative data on the state and functioning of agricultural production processes using sensors: atmospheric, soil, phenological, etc. and wireless probes: optical, physical and chemical;

- creation of a collective use center "Analytical laboratory of viticulture and winemaking", including a laboratory for analysis of soil and soil grounds and a laboratory for research of grape processing products;

- creation of a distributed (blockchain) soil and plant monitoring system within a separate training ground based on the analysis of big data generated by sensors and unmanned aerial vehicles in order to assess the impact of environmental factors on the process of growing grapes and recognizing plant diseases.

Fig.2 shows the proposed organizational structure of the "Digital Quality Center" (with the status of a limited liability company, a small and medium-sized enterprise).

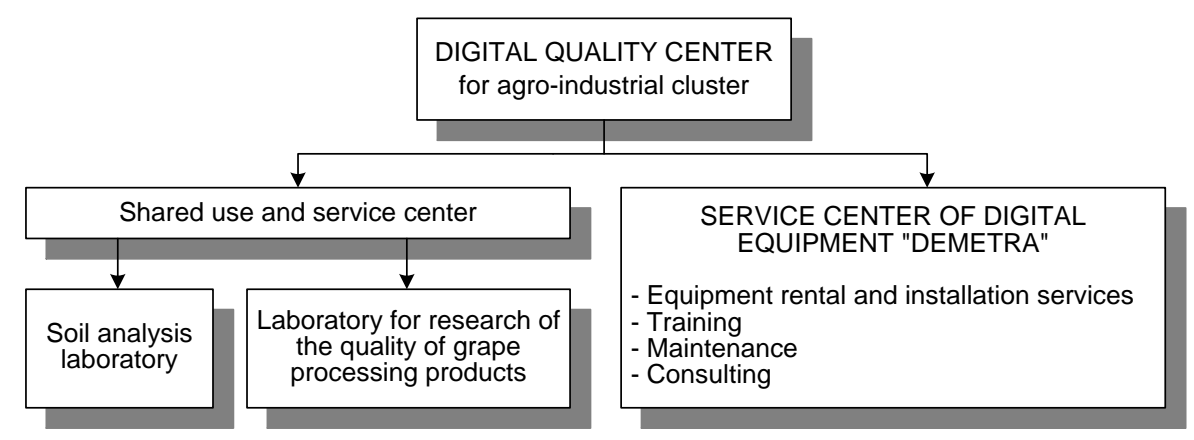

Fig. 2. Organizational structure of the "Digital Quality Center".

Considering that in the field of viticulture and winemaking on the territory of the Sevastopol agro-industrial cluster, there are more than 30 enterprises and farms (wineries) located at a considerable distance from each other, to create and full-scale functioning of the system of "precision viticulture" using the meteorological platform "Demetra" (including sensors) an appropriate number of sets of equipment is required. As a result, their total cost may be 120 million Rubles at the rate of 4 million per set (including installation of sensors).

However, since the capabilities of the SMART-BOX station (the basic element in the set of equipment) are redundant for the needs of an individual wine-making economy, it seems expedient to connect nearby agricultural enterprises to the station, including those specializing in other areas of the agro-industrial complex.

\section{Discussion}

The organization of financial support and support for joint projects within the agro-industrial cluster is carried out by a specialized organization of the cluster, the founders of which must be at least $50 \%$ of its participants. The initiators of the joint project, which may be interested cluster members, should become the founders of the Digital Quality Center organization and participate in co-financing the project. In this case, they can be large wineries in Sevastopol.

As an alternative, the scenario of joint financing of the project by its initiators can be considered with the possible involvement of additional sources:

- funds from the budget of the city of Sevastopol in the form of subsidies for co-financing the costs of creating and operating industrial infrastructure facilities;

- investment lending by financial organizations of the city; 
- concessional leasing under programs implemented through a network of regional leasing companies under the guarantee fund for support of small and medium-sized businesses in Sevastopol [3-10].

Another financing option is to raise funds within the framework of a public-private partnership agreement with the City Government, since the project is infrastructural and ensures the development of one of the agro-industrial complex key sectors (viticulture and winemaking), which is provided for by the Strategy for the Socio-Economic Development of the City of Sevastopol until 2030.

The choice will depend on two factors: the results of the assessment of the financial and economic efficiency of the project, which is planned to be carried out in the course of further research, and the availability of interested project participants who are ready to become its initiators [11].

\section{Conclusion}

The results of the study allow us to establish the presence of a number of problems hindering the development of the industry. Many of them are of a systemic nature (for example, the problem of water supply, etc.), therefore, this topic requires further study. Nevertheless, it already seems possible to draw the following main conclusions.

- In the Sevastopol region, there is a large number of vine plantations requiring reclamation, as well as a high thinning of fruit-bearing vineyards;

- Three quarters of Sevastopol vineyards are planted in non-irrigated areas;

Soil and climatic conditions, limited water resources and an almost complete ban on the use of pesticides on grape plantations located near settlements and natural reservoirs (river floodplains) make it possible to characterize the Sevastopol viticulture as carried out in conditions of risky agriculture already due to the need for higher costs for reducing the adverse consequences of the manifestation of these factors.

- Nevertheless, this sector of the agro-industrial complex has a fairly high investment attractiveness, since the technical characteristics of grape raw materials harvested in this territory are competitive in comparison with both domestic and imported wine materials.

- Taking into account the peculiarities of the consumer market of wine products, the main task, the solution of which will ensure the further successful development of the industry in the Sevastopol region, is to reduce costs in the process of growing grapes and increase its yield, which will provide an opportunity to optimize the selling price of wine, as well as improve the quality of grape raw materials and finished products.

- The solution to this problem is possible through the use of quality control technology in the system of precision viticulture in the agro-industrial cluster of Sevastopol. The production system, positioned as "precision viticulture", makes it possible to control the technological process of growing vines from the moment of planting to the moment of fruiting, ripening and grape harvest, thereby ensuring that the planned yield and quality of the future wine material will be achieved.

- Analysis of the technical and economic characteristics of the project of precision viticulture using the meteorological platform "Demetra" showed that its implementation will allow:

- improve the quality of wine products produced on the territory of the agro-industrial cluster of Sevastopol;

- to reduce the use of pesticides for processing plants;

- to optimize the number of staff as a result of reducing manual labor associated with the maintenance of vineyards;

- to stimulate the development of small and medium-sized wineries producing premium-class products, integrating them into the tourism sector of the city in order to popularize the quality of wine from local producers and expand the sales market [12-15]. 
- In order to consolidate the activities of cluster members, it seems expedient to separate into a separate joint infrastructure project "Creation of a digital quality center", which will provide for the cluster members:

- collective access to equipment and services for the analysis of various types of soils of the Crimean region, as well as grapes, wine, wine materials, juices, must, etc. in order to control the current and forecast the potential quality of viticulture and winemaking products, which will help to increase the economic efficiency of production;

- the possibility of using, on a lease basis, sets of equipment of the meteorological platform "Demetra" for the organization of a digital control system for the cultivation of grapes from the seedling to the production of grape raw materials.

- It seems appropriate to study in detail the possibilities and options for financial support for innovative programs for the development of viticulture and winemaking in the agro-industrial cluster of Sevastopol using both federal and regional sources of funding.

\section{References}

1. O.N. Sheludko, T.I. Guguchkina, N.K. Strizhov, T.V. Guzik, Analytics and control, 22(3), 315 (2018)

2. O.N. Sheludko, T.I. Guguchkina, N.K. Strizhov, Scientific works of SKFNTsSVV, 23, 235 (2019)

3. E.V. Ostroukhova, I.V. Peskova, P.A. Probeigolova, N.Yu. Lutkova, O.V. Zaitseva, S.A. Eremenko, Viticulture and winemaking, 20(3), 77 (2018)

4. O.Yu. Tarkhanova, Problems of informatics, 4, 10-31 (2017)

5. O.D. Ermolenko, INFORMAGRO-2020, 259 (2020)

6. S. Shanmuganthan, A. Ghobakhlou, P. Sallis, Sensor data acquisition for climate change modeling, 7(11), 942 (2008)

7. H. M. Jawad, R. Nordin, S. K. Gharghan, A. M. Jawad, M. Ismail, Sensors 17, 1781 (2017)

8. D.V. Cheremysynova, E.A. Posnaya, Financial research, 3, 154 (2020)

9. Y.V. Melnikova, B.A. Bukach, A.V. Shokhnekh, S.V. Tarasenko, E3S Web of Conferences, 161, 01105 (2020)

10. E.A. Posnaya, O.I. Ditsulenko, A.M. Kolesnikov, A.V. Shokhnekh, European Proceedings of Social and Behavioral Sciences EpSBS, 402 (2020).

11. V.V. Manuylenko, L.A. Kabardokova, M.A. Loktionova, N.V. Sobchenko, T.A. Sadovskay, European Research Studies Journal, XX, 2B, 439 (2017)

12. V.V. Manuylenko, M.A. Loktionova, N.V. Lipchiu, N.V. Sobchenko, T.A. Sadovskaya, The International Journal Entrepreneurship and sustainability issues, 6 (2), 871 (2018)

13. E.A. Posnaya, M.I. Kaznova, I.E. Shapiro, I.G. Vorobyova, European Research Studies Journal, XXI, 497 (2018)

14. N.V. Gryzunova, V.I. Pyatanova, V.V. Manuylenko, K.V. Ordov, Entrepreneurship and sustainability issues, 7(1), 615 (2019)

15. V.V. Manuylenko, L.A. Kabardokova, M. N.Koniagina, V.N. Glaz, T.A. Sadovskay, Journal of Applied Economic Sciences XIII, 2 (56), 454 (2018) 